The Relationship between Goal Orientation and Career Striving in Young Adolescents

Authors: $\quad$ Peter Creed ${ }^{1}$, Nick Buys ${ }^{2}$, Clare Tilbury ${ }^{2}$, and Meegan Crawford ${ }^{2}$

Affiliations: Griffith University, Australia

${ }^{1}$ School of Applied Psychology, and Griffith Health Institute

${ }^{2}$ School of Human Services and Social Work, and Griffith Health Institute 
Contact: $\quad$ Prof Peter Creed

School of Applied Psychology

Griffith University, Gold Coast, QLD 4222, Australia

Email: p.creed@griffith.edu.au 


\title{
The Relationship between Goal Orientation and Career Striving in Young Adolescents
}

\begin{abstract}
We surveyed 280 students ( $61 \%$ girls; $M=15.3$ years) and, in the context of goal setting theory and selfregulation, tested a cross-sectional model in which goal orientation (learning, performance-prove, performance-avoid) was viewed as an antecedent to self-efficacy and outcome expectations, selfefficacy and outcome expectations were tested as antecedents to goal setting, and goal setting tested as an antecedent to career striving behaviours (exploration, planning). After controlling for educational achievement, learning orientation was directly, positively, associated with self-efficacy and outcome expectations, and indirectly associated with career aspirations, career exploration and planning, and performance-avoid orientation was negatively associated with self-efficacy. The study demonstrated that goal orientation is an important variable to consider when examining career development in adolescents.
\end{abstract}

Keywords: goal orientation; goal setting; self-regulation; career striving; self-efficacy; outcome expectations, career planning; career exploration 


\section{The Relationship between Goal Orientation and Career Striving in Young Adolescents}

\section{Goal Setting and Self-regulation}

In recent years, adolescent career development has been increasingly characterised as career adaptability (Creed, Fallon, \& Hood, 2009; Hirschi, 2009), which is defined as "the readiness to cope with the predictable [and unpredictable] tasks of preparing for and participating in the work role" (Savickas, 1997; p. 254), or as "the way an individual views his or her capacity to plan and adjust to changing career plans... especially in the face of unforeseen events" (Rottinghaus, Day, \& Borgen, 2005; p. 5). These definitions construe career adaptability as self-regulatory thoughts and behaviours associated with managing the steps and processes of achieving career-related goals, such as deciding on a career that will satisfy, obtaining the training required for the career, and making the transition to paid employment. From a goal setting perspective (cf. Locke \& Latham, 2002), self-regulatory behaviours are implemented to diminish the discrepancy between where an individual seeks to be and their current situation (Kanfer, Wanberg, \& Kantrowitz, 2001; Maes \& Karoly, 2005).

A potentially important antecedent to self-regulatory processes is one's goal orientation, which has been conceptualised as a somewhat stable, trait-like characteristic that operates as the mental framework within which individuals appraise and react to achievement situations, such as meeting career-related goals (Payne, Youngcourt, \& Beaubien, 2007). Most literature suggests three types of goal orientation, learning, performance-prove, and performance-avoid, which, in achievement situations, affect the individual's level and type of goal attainment by influencing the type and quality of selfregulation that is employed; that is, goal orientation influences "the quality, timing, and appropriateness of cognitive strategies that... control the quality of one's accomplishments" (Covington, 2000, p. 174). 
The current study examined several aspects of career development from a self-regulatory and goal setting perspective. We report on career aspirations (i.e., career goals), the career behaviours associated with achieving those aspirations (i.e., career exploration and career planning), the social-cognitive influences on the development of career aspirations (i.e., perceptions of self-efficacy and outcome expectation beliefs), and the trait-like strategies of goal orientation (i.e., learning, performance-prove, and performance-avoid goal orientation), which can be considered individual or person inputs that contribute to career development (Lent, 2005), and which reflect the individual's preferred manner of pursuing achievement-related goals (Elliot \& Harackiewicz, 1996).

The perspective taken in this paper is consistent with goal setting theory generally, for example, where goals are identified, plans are made, goal striving behaviours occur, goals are evaluated and revised, and outcomes are met, or not met (Locke \& Latham, 2002; Lord, Diefendorff, Schmidt, \& Hall, 2010). It is also consistent with specific career goal setting models, such as social-cognitive career theory (Lent, Brown, \& Hackett, 1996). Social-cognitive career theory proposes that the three key variables of self-efficacy, outcome expectations, and goal setting represent personal agency, or adaptability, in the career domain, mediate past experiences and more stable person-traits, and drive career-related behaviours. These three key variables have been described as the building blocks of career development (Lent et al., 1996, p. 380). As career aspirations are important life goals, examining career development from a goal setting and self-regulatory perspective is likely to extend our understanding of how young people set career-related goals and go about meeting them.

\section{Career Aspirations}

For the purpose of this study, we operationalised career goals as career aspirations, which are "an individual's expressed career-related goals or choices" (Rojewski, 2005, p 132). Aspirations are central to the career choice process, as they influence educational and training decisions and are strongly 
associated with future occupational selection and achievement (Mau \& Bikos, 2000; Schoon \& Parsons, 2002). Career goals (i.e., career aspirations) drive the motivational processes and striving behaviours that the individual sets in train to assist with goal achievement. Career aspirations can be considered at multiple levels. They reflect an individual's goal for a specific occupational area (e.g., the desire to work in the health area) or a specific occupation (e.g., the desire to be a medical practitioner), but also are considered along multiple other dimensions, including level of prestige, traditionality, the training required, and lifestyle (Creed, Searle, \& Rogers, 2010). We operationalised career aspirations as leadership aspirations, which reflect the level of authority and responsibility desired in a career.

\section{Career Striving Behaviours}

We operationalised career goal striving as career exploration and planning, which are important career striving behaviours that help to convert career aspirations into actual career outcomes for the individual (Lent et al., 1996). Career planning relates to the thinking and preparation one undertakes for the future; whereas career exploration involves the gathering of information about the self and the environment, primarily the world of work, that is relevant to making career related decisions (Blustein, 1997). Both are ongoing, life-long activities that typically come into focus in a crisis or during a transition (Zikic \& Klehe, 2006), and both have been associated with success in the career domain (Hall, 2002).

\section{Social-Cognitive Variables}

Consistent with social-cognitive career theory, we considered self-efficacy and outcome expectations as antecedents to career aspirations. Career self-efficacy refers to an individual's beliefs about his/her capacity to carry out successfully the tasks associated with achieving career-related goals, whereas outcome expectations represent contingency beliefs about the likely outcome of performing a particular task (Bandura, 1986; Lent, Brown, \& Hackett, 2000). The antecedents that influence the development of self-efficacy and outcome expectations are the personal characteristics and environmental experiences 
of the individual, which include predispositions to think and act in particular ways, past accomplishment experiences, vicarious learning and modeling, encouragement from others, and the ability to manage the emotions associated with a task. From this perspective, elevated self-efficacy and outcome expectations result from experiencing success, having successful models to learn from, receiving appropriate encouragement for tasks, and, for example, being able to manage anxiety when engaging in career development behaviours. Outcome expectations for the individual are dependent also on self-efficacy beliefs, as self-efficacy increases (or decreases) the probability of the individual setting a particular goal or engaging in a particular goal-striving behaviour.

There is considerable research evidence from both adult and children populations that suggests that the particular goal orientation of the individual directly affects goal setting and goal striving behaviours (e.g., Payne et al., 2007; Utman, 1997; Valentini \& Rudisill, 2006). Further, goal orientation has been characterised as an antecedent to task specific efficacy (e.g., career self-efficacy) and expectations of success (Payne et al., 2007; Valentini \& Rudisill, 2006). Thus, the aim of the current study was to test a goal setting and self-regulatory model, in which goal orientation, construed as a predisposition to manage achievement tasks in a particular manner, was an antecedent to self-efficacy and outcome expectations, where the social-cognitive variables of self-efficacy and outcome expectations were antecedents to goal setting, and where goal setting was an antecedent to career striving behaviours. Consistent with previous research and theory, we also expected self-efficacy to be a proximal antecedent to outcome expectations. See Figure 1 for a visual representation of this model.

\section{$\underline{\text { Insert Figure } 1 \text { about here }}$}

There is extensive support in the career literature for the relationships among self-efficacy, outcome expectations, goal setting, and striving behaviours (Betz \& Hackett, 2006). However, few studies have tested the influence of goal orientation on the beliefs and behaviours around career development. Creed 
et al. (2009) showed that the goal orientation of university students was associated with several careerrelated variables, including career exploration and career decision-making, while Creed, Tilbury, Buys, and Crawford (2011) tested a cross-lagged model across two time points and found support for goal orientation as a precursor to career aspirations in high school students. The remainder of this introduction will focus on the potential effects of goal orientation on career development.

\section{Goal Orientation}

From a goal orientation perspective, individuals interpret, experience and behave differently in achievement situations depending on whether they adopt a learning, performance-prove, or performance-avoid orientation (Dweck, 1986; Dweck \& Leggett, 1988). Individuals with a high learning goal orientation are likely to set difficult and challenging goals. They do this as they see it as the way of developing competencies and capital. This occurs as they view ability as a flexible characteristic, which can be fostered and developed through challenge. Learning oriented individuals believe outcomes are contingent on effort. Thus, they are more engaged in behaviours, such as planning and goal striving, which, in turn, increases the probability of them meeting their goals. As they view ability as flexible and able to be developed, poor performance, setbacks, and obstacles are interpreted as feedback on their efforts. Consistent with goal setting theories, including social-cognitive career theory, which incorporate feedback loops, this feedback then either fosters increased effort and application, or triggers goal or strategy revisions (VandeWalle, Brown, Cron, \& Slocum, 1999). Learning oriented individuals also experience more positive outcomes as they seek higher challenges, invest more effort, are more persistent, and are more likely to accept feedback on their efforts and revise their strategies. Thus, having a predisposition to a learning orientation promotes "the establishment, maintenance, and attainment of personally challenging and personally valued achievement goals" (Dweck, 1986; p. 1040). Consistent with this, reviews of the area have demonstrated positive relationships between a learning 
goal orientation and knowledge acquisition and academic achievement in children (Valentini \& Rudisill, 2006), and between a learning goal orientation and job performance in adults (Payne et al., 2007). In the careers' area, those with a high learning goal orientation should set higher career goals, be more engaged in their achievement, and have more positive outcomes.

Learning and performance-prove goal orientations are both approach orientations (Elliot \& Thrash, 2002). In approach orientations, individuals are focused on achievement and success; whereas avoidant orientations (i.e., performance-avoid orientation) involve motivation strategies that seek to avoid negative outcomes (Jackson, Hobman, Jimmieson, \& Martin, 2009). However, unlike those with a learning orientation, individuals with a performance-prove orientation view ability largely as a fixed characteristic; one that is difficult to develop. As a result of this, they are focused on gaining favourable feedback from others on the ability/competence they have, which they do by demonstrating their prowess and achieving success (Dweck, 1986; Dweck \& Leggett, 1988). Thus, individuals with a high performance-prove goal orientation also will set high goals also, especially where success is likely, as this can lead to receiving positive feedback from others on their ability and accomplishments. Positive effects result from a performance-prove goal orientation more often in situations where tasks can be easily mastered and are fairly routinised, rather than when they are complex and demanding (Davis, Carson, Ammeter, \& Treadway, 2005). Consistent with this, performance-prove individuals are less engaged in goal striving behaviours, as, to them, effort is an indication of low ability. Further, persistence is poor as goals generated to demonstrate ability are less likely to be motivating intrinsically and sustaining of interest and effort. Thus, those with a performance-prove orientation might set high goals, as these reflect an orientation to do better than others, but might expend less effort and persistence in achieving them as they are not intrinsically rewarding, and be less successful at goal achievement. Research to date has demonstrated mostly positive relationships between a performance-prove orientation and 
performance outcomes, although the effects are generally weaker than those for learning goal orientation (Payne et al., 2007; Yeo, Sorbello, Koy, \& Smillie, 2008).

Finally, a performance-avoid goal orientation is an avoidant rather than an approach orientation (Elliot \& Thrash, 2002). Performance-avoid individuals, like performance-prove individuals, also hold a fixed view of ability, but seek to protect their view of themselves by avoiding being seen as incompetent. Thus, they set low goals to reduce the risk of negative outcomes, failure, and adverse feedback from others. This orientation also stimulates self-protection processes such as effort withdrawal and selfhandicapping, which interfere with goal striving motivations and behaviours and reduce goal achievement (Elliot, Shell, Bouas Henry, \& Maier, 2005; VandeWalle, 1997). Those high on performanceavoid orientation are reluctant to ask for help, feel anxious about scrutiny as this might disclose a lack of ability, and are less confident in their capacity to carry out tasks and achieve outcomes (Middleton \& Midgley, 1997). Empirical studies have consistently identified negative relationships between a performance-avoid orientation and striving and performance in adults (Payne et al., 2007), children, and adolescents (Valentini \& Rudisill, 2006).

\section{Hypotheses}

Thus, based on the goal orientation literature, we expected the approach orientations (learning [H1] and performance-prove [H2]) to be associated positively with career self-efficacy and outcome expectations, and expected the avoidant orientation (performance-avoid [H3]) to be associated negatively with career self-efficacy and outcome expectations. Based on the social-cognitive career literature, we expected career self-efficacy to be associated positively with outcome expectations [H4] and career aspirations [H5], outcome expectations to be associated positively with career aspirations [H6], and career aspirations to be associated positively with the career striving behaviours of exploration [H7] and planning [H8]. As self-efficacy and outcome expectations are considered the most proximal 
variables to goal setting, and to mediate antecedent person and contextual variables, we expected career self-efficacy and outcome expectations to mediate the relationship between goal orientation and career aspirations [H9], and, as self-efficacy, outcome expectations and goal setting have been conceptualised as driving career-related striving behaviours, we expected career self-efficacy, outcome expectation and career aspirations to mediate the relationship between goal orientation and the career striving behaviours of exploration [H10] and planning [H11]. See Figure 1.

\section{Method}

\section{Participants}

We surveyed 287 high school students in Queensland, Australia. Seven surveys were discarded as they had been started but not completed. The remaining 280 students comprised 172 girls (61.4\%) and 108 boys, with a mean age of 15.3 years $(S D=1.2)$. There were 124 students $(44.3 \%)$ enrolled in Junior High (Grades 8 and 9) and 156 enrolled in Senior High (Grades 10 to 12).

\section{Materials}

The survey contained measures of goal orientation, self-efficacy, outcome expectations, career aspirations, career exploration and planning. We also assessed age, grade, gender, and self-reported level of school achievement. Unless otherwise indicated, the students responded to scale items using a 5-point Likert-like response format with endpoints of $1=$ strongly disagree and $5=$ strongly agree, with higher scores representing higher levels of a construct.

Career aspirations. We measured an important domain of career aspirations that is related to the goal of achieving highly in one's career. Individuals, who want to do well in their career aspire to leadership positions, want to be promoted, and commit to additional education and training. Based on a factor analysis reported by Gray and O'Brien (2007), we selected four items from the Aspiring to 
Leadership and Promotions subscale of the Career Aspirations Scale (O'Brien, 1996). This scale taps aspirations to becoming a leader and being promoted when in work. Sample items were, "When I am established in my working life: I would like to manage other workers / I would like to become an expert in my field". O'Brien reported an internal reliability coefficient of .74 with the full scale, and found significant associations for the scale with career salience, academic achievement, and career selfefficacy in support of construct validity. We conducted a confirmatory factor analysis (CFA), which indicated a good fit for a single factor, $\chi^{2}(2)=4.90, p=.09, \chi^{2} / d f=2.45, \mathrm{CFI}=.99$, RMSEA $=.07$; internal reliability was .70 .

Career striving behaviours. We measured two career goal striving behaviours: career exploration and career planning. These were assessed using two subscales of the Career Development Inventory Short Form (Creed \& Patton, 2004; Lokan, 1984). The 8-item career exploration subscale taps the type and usefulness of career exploration undertaken (e.g., "Would you ask any of these people for information or help to make plans for work or further education...?", with options such as teachers and guidance officers). The 10-item career planning subscale assesses the range and degree of career planning undertaken (e.g., "How much have you thought and planned about choosing a career in general?", with endpoints of Not much at all and A great deal). Creed and Patton (2004) reported internal reliabilities of .73 (exploration) and .87 (planning), and found support for construct validity by demonstrating positive associations between the two scales and career self-efficacy and career decidedness, strong correlations between the short-form and long-form versions of the scales, and by finding age and gender differences in the expected directions. CFA analyses produced satisfactory fit statistics for single factors for both exploration, $\chi^{2}(16)=37.74, p=.002, \chi^{2} / d f=2.36$, CFI $=.95$, RMSEA $=.07$, and planning, $\chi^{2}(28)=38.73, p=.09, \chi^{2} / d f=1.38, \mathrm{CFI}=.99, \mathrm{RMSEA}=.04 ;$ alphas were .73 and .86 , respectively. 
Career self-efficacy. Fouad, Smith, and Enochs (1997) constructed a 12-item scale to measure how confident students were in carrying out a range of tasks associated with choosing a career. This 12 -item scale used selected questions from the 50-item Career Decision-making Self-efficacy Scale (Taylor \& Taylor, 1983). Sample items were, "How confident are you that you could find information in the library about a career you were interested in?", and "How confident are you that you could choose a job that would suit your interests?". We used nine items from the Fouad et al. scale, deleting three items that were not suitable for our sample (e.g., “...choose a career in which most workers are the opposite sex?”). Fouad et al. reported an internal reliability of .79 , and demonstrated validity by showing that the scale was structurally independent of, but positively related to, other career scales such as career outcome expectations and career goals. A CFA produced a satisfactory fit for a single factor for the nine items, $\chi^{2}(23)=29.36, p=.17, \chi^{2} / d f=1.28, \mathrm{CFI}=.99, \mathrm{RMSEA}=.03 ;$ alpha was .87.

Career outcome expectations. We used nine questions based on the format of the 5-item Career Decision Making Outcome Expectancy Scale (Fouad et al., 1997), which used conditional statements (i.e., if I do this, then I expect that) to tap career expectations in relation to effort expended. A sample item from the Fouad et al. scale is, "If I know about the education I need for different careers, I will make a better career decision". We included four additional items to assess a broader construct and to give the opportunity to delete items that did not work (sample items that we included were, "The time I spend deciding upon the right job will be worth it", and "The time I spend on my education will be worth it to get the job I am interested in"). Fouad et al. reported an alpha of .70 for their five items, demonstrated scale independence from, and positive associations with, other career-related scales (career self-efficacy, career goals). A CFA identified a satisfactory fit for one factor for the nine items, $\chi^{2}(23)=54.12, p<.001$, $\chi^{2} / d f=2.35, \mathrm{CFI}=.98, \mathrm{RMSEA}=.07 ;$ alpha was .92 . 
Goal orientation. We assessed three aspects of goal orientation, namely learning, performance-prove, and performance-avoid orientations. Urdan and Midgley (2003) generated 18 items to assess goal orientation, and used these with a sample of high school students. We selected nine of the most appropriate items for our study. These items were phrased as general orientation (e.g., "I like school work...) rather than specific (e.g., "I like maths work...). Sample items were, "I like school work that I will learn from, even if I make a lot of mistakes" (learning), "I'd like to show my teachers that I'm smarter than the other students in my class" (performance-prove), and "It's very important to me that I don't look stupid in my class" (performance-avoid). Urdan and Midgley reported satisfactory internal reliability coefficients for their learning ( 6 items; alpha ranged from .80 to .86 for children across grades 5 to 7 ), performance-prove (6 items; $\alpha=.84$ to .86 ), and performance-avoid measures (6 items; $\alpha=.78$ to .82 ). Urdan and Midgley's three measures were independent of one another, and support for construct validity was demonstrated by finding associations in the expected directions with scales of academic efficacy, learning strategies, and affect at school (Midgley et al., 1998). A CFA demonstrated that a three factor model for our 3-item measures fit our data well, $\chi^{2}(20)=41.54, p=.003, \chi^{2} / d f=2.08, \mathrm{CFI}=.97$, RMSEA $=.06$. Our three measures were related to other scales in the study in the expected direction using zero-order and latent variable correlations (see Table 1). The internal reliability coefficients were $.81, .76$ and .60 , respectively.

\section{Procedure}

Teachers distributed the surveys in class time in the students' homerooms. Students were encouraged to complete the survey in their own time and return it in a sealed envelope to the teacher. As an encouragement to participate, we offered students who returned their survey to have their names placed in a draw to win a prize. About $50 \%$ of students in the school returned a survey. The study was conducted under the auspices of the authors' university ethics' committee. 


\section{Results}

\section{Data Management}

We replaced missing Likert item responses with the person mean for that scale. This procedure has been recommended by Roth, Switzer, and Switzer (1999) for managing item-level (rather than variablelevel) missing data where the pattern of missing data is either random or systematic.

We created latent variables using a combination of observed items and multi-item parcels. The learning, performance-prove, and performance-avoid goal orientation latent variables were each represented by three individual observed items; the aspirations latent variable was represented by four observed items. We created multi-item parcels to represent self-efficacy, outcome expectations, and career exploration and planning, which were longer scales. The procedure for creating the multi-item parcels was to subject the items of each scale to separate exploratory factor analyses where the extraction was restricted to one factor. We then allocated the highest and lowest loading items to the first parcel, the second highest and lowest to the second parcel, and the third highest and lowest to the third parcel, and repeated these steps until all items were exhausted. Parcels were then formed by summing the items allocated to them (see Landis, Beal, \& Tesluck, 2000).

\section{Model Testing}

We assessed (a) the measurement model for the variables being tested, and (b) the hypothesized structural model. As several authors have suggested testing alternate models to the hypothesised model to help clarify different plausible causal sequences (e.g., Byrne, 2010; Kline, 2011), we also assessed (c) two additional structural models and tested their fit against the fit of the hypothesised model. Next, (d) we examined whether self-efficacy and outcome expectations mediated the relationship between goal orientation and career aspirations, and (e) examined whether self-efficacy, outcome expectations and career aspirations mediated the relationship between goal orientation and the career striving behaviours. 
As educational achievement was significantly, bivariately associated with all model variables, we controlled for this in all analyses by modelling the association between educational achievement and all endogenous variables. We found no meaningful associations between age or gender and model variables, and thus, excluded these variables from the analyses. See Table 1 for bivariate correlations.

\section{$\underline{\text { Insert Table } 1 \text { about here }}$}

Analyses were conducted using maximum likelihood estimation within the AMOS software. We examined $\chi^{2}$, the Comparative Fit Index (CFI) and the Root Mean Square Error of Approximation (RMSEA) as indices of fit for the models (Byrne, 2010). The $\chi^{2}$ and CFI indices compare a specified model to one with complete independence, with a non-significant $\chi^{2}$ and CFI values $>.90$ to .95 indicating a good model fit. The RMSEA estimates the error due to the approximate fit of the model. The less error the better; thus, RMSEA values $<.05$ to .08 are desirable. As the $\chi^{2}$ statistic is sensitive to sample size (the

more participants, the higher the $\chi^{2}$ value), it is recommended that it be used with caution and to consider also a $\chi^{2}$ value two to three times greater than the degrees of freedom as acceptable (Byrne, 2010). Thus, we also considered the $\chi^{2} / \mathrm{df}$ statistic.

\section{Predicting Aspirations and Striving Behaviours}

First, we used confirmatory factor analysis to test if all items and multi-item parcels represented the latent variables as intended. This measurement model consisted of the eight latent variables representing goal orientation (learning, performance-prove, performance avoid), self-efficacy, outcome expectations, career aspirations and career striving behaviours (planning and exploration), and included the observed variable of educational achievement. The eight latent variables and educational achievement were allowed to covary freely. The fit statistics, $\chi^{2}(261)=443.98, p<.001, \chi^{2} / \mathrm{df}=1.70, \mathrm{CFI}$ $=.95, \mathrm{RMSEA}=.05$, demonstrated a satisfactory fit for these data. Table 1 reports correlations among the latent variables. 
Second, we tested the hypothesized structural model shown in Figure 1, while controlling for educational achievement. This model produced satisfactory fit statistics, $\chi^{2}(272)=465.38, p<.001, \chi^{2} / d f$ $=1.71, \mathrm{CFI}=.95, \mathrm{RMSEA}=.05$. Three hypothesised model pathways (performance-avoid $\rightarrow$ outcome expectations, performance-prove $\rightarrow$ self-efficacy, performance prove $\rightarrow$ outcome expectations) and four educational achievement pathways (educational achievement pathways to self-efficacy, aspirations, exploration, and planning) were progressively removed as they were not significant. This final model (see Figure 2) also produced a satisfactory fit, $\chi^{2}(279)=475.60, p<.001, \chi^{2} / d f=1.69, \mathrm{CFI}=.95, \mathrm{RMSEA}=.05$. Learning goal orientation and performance-avoid orientation accounted for $32.7 \%$ of the variance in selfefficacy. Learning goal orientation, self-efficacy and educational achievement accounted for $66.6 \%$ of the variance in outcome expectations. Self-efficacy and outcome expectations accounted for $68.0 \%$ of the variance in career aspirations. Finally, career aspirations accounted for $53.0 \%$ of the variance in career exploration, and $36.8 \%$ of the variance in career planning.

\section{Alternate Model Testing}

As goal orientation might relate to the other variables in the hypothesised model in different ways (i.e., apart from goal orientation being conceived as the most distal variables to career exploration and career planning), we assessed two plausible, alternate models. The first was that self-efficacy and outcome expectations would predict the goal orientation variables, which in turn would predict aspirations and then exploration and planning. This model is plausible as, for example, having higher selfefficacy and outcome expectations might lead to a reduced performance-avoid orientation as the goal outcome is perceived as achievable. The second model was that self-efficacy and outcome expectations would predict aspirations, that aspirations would predict the goal orientation variables, which in turn would predict exploration and planning. This model is also reasonable as, for example, having higher aspirations might lead to an increased performance-prove orientation as an achievement orientation is 
required to meet these goals. We compared these two alternate models against the hypothesised model presented in Figure 1 using the standard fit statistics and the Akaike Information Criterion (AIC), which assesses for parsimony among competing non-hierarchical models that use the same data (Kline, 2011). The fit indices for the first, $\chi^{2}(277)=488.08, p<.001, \chi^{2} / \mathrm{df}=1.76, \mathrm{CFI}=.94$, RMSEA $=.05$, and second alternate models, $\chi^{2}(274)=476.86, p<.001, \chi^{2} / d f=1.74, \mathrm{CFI}=.95$, RMSEA $=.05$, were acceptable and only marginally poorer than the final hypothesised model. However, the hypothesised model was accepted as the preferred model as this model produced the lowest AIC statistic (619.60 vs. 636.08 and 630.86, respectively), and was thus the most parsimonious.

\section{Insert Figure 2 about here}

\section{Tests of Mediation}

In the final structural model, career self-efficacy and outcome expectations potentially mediated the relationship between goal orientation (learning and performance-avoid) and career aspirations (both goal orientation latent variables were bivariately associated with career aspirations; see Table 1). Career self-efficacy, outcome expectations and career aspirations potentially mediated the relationship between learning goal orientation and career exploration and career planning, as this predictor variable alone was bivariately correlated with the two career striving outcome variables (see Table 1). We followed the recommendations of Shrout and Bolger (2002) to test if these mediation pathways were significant. For each pathway, we tested two structural models, one that tested the direct effects only (e.g., learning goal orientation predicting career aspirations), and one that tested both the direct and indirect effects. We used the AMOS bootstrapping procedure with 1000 samples to estimate standard errors and $90 \%$ bias-corrected confidence intervals for all direct and indirect estimates. Mediation occurs when the predictor is significantly associated with the outcome, the mediator is significantly associated 
with both the predictor and the outcome, and the $90 \%$ confidence intervals of the indirect effect via the mediator do not include zero.

When we tested the direct paths, learning goal orientation $(\beta=.45 ; p<.001)$, but not performanceavoid goal orientation $(\beta=-.10 ; p=.23)$, was associated significantly with career aspirations (after controlling for educational achievement). Thus, only learning goal orientation met this criterion for mediation. Additionally, learning goal orientation was associated significantly with career planning ( $\beta$ $=.57 ; p<.001)$ and career exploration $(\beta=.54 ; p<.001)$, again after controlling for educational achievement. When we tested the direct and indirect effects together, learning goal orientation was no longer directly associated with career aspirations $(\beta=-.06 ; p=.45)$, and the confidence intervals did not contain zero $(\mathrm{Cl}=.22$ to .44$)$, indicating that career self-efficacy and outcome expectations fully mediated the relationship between learning goal orientation and career aspiration. Using the same procedures, when we examined the indirect relationship between learning goal orientation and career exploration and planning, we found full mediation effects for learning goal orientation on career planning $(\beta=.12 ; p=.09 ; \mathrm{Cl}=1.02$ to 1.91$)$ and a partial mediation effect for career exploration $(\beta=.19$; $p=.02 ; \mathrm{Cl}=.37$ to .89$)$.

\section{Discussion}

The present study used a self-regulatory and goal oriented approach to career development and tested the relationship between goal orientation (learning, performance-prove, performance-avoid) and several important career-related variables (career self-efficacy, outcome expectations, aspirations, and striving behaviours). We proposed a model in which goal orientation was an antecedent to career selfefficacy and outcome expectations, where self-efficacy predicted outcome expectations and career aspirations, outcome expectations also predicted career aspirations, and where career aspirations 
predicted the career striving behaviours of planning and exploration. This model controlled for the effect of educational achievement.

Consistent with social-cognitive career theory (Lent et al., 1996), we found the relationships among the social-cognitive variables to be as expected: career self-efficacy was associated positively with outcome expectations ( $\mathrm{H} 4)$ and career aspirations (H5), outcome expectations was associated positively with career aspirations (H6), and career aspirations was associated positively with the career striving behaviours ( $\mathrm{H} 7$ and $\mathrm{H} 8$ ). These results are consistent with the general career development literature (e.g., see Betz \& Hackett, 2006), and support the external validity of the study, suggesting the results can be generalised to other similar populations. They also reinforce the value for young people of developing specific career related self-efficacy and a contingency relationship between effort and outcomes, as these are associated with higher career aspirations as well as career-related planning and exploration. Thus, interventions that foster career confidence and the value of personal effort in the career domain are likely to advantage young people directly, as well as benefit them in other career development domains.

We found a learning goal orientation to be associated positively with career self-efficacy and outcome expectations ( $\mathrm{H} 1)$, and found a performance-avoid orientation to be associated negatively with career self-efficacy (partially supporting $\mathrm{H} 3$ ). These results are consistent with the general research on goal orientation (e.g., see Payne et al., 2007), which has shown that, on the one hand, efficacious individuals display a learning goal orientation, and that, on the other, it is those who have a performance-avoid orientation, who are more likely to employ self-defeating behaviours. Fostering a learning orientation generally, and specifically in relation to career development, and intervening when young people have a performance-avoid orientation should advantage young people in their career development. 
Additionally, career self-efficacy and outcome expectations mediated the relationship between a learning goal orientation and career aspirations (partially supporting H9), and self-efficacy, outcome expectations, and career aspirations mediated the relationship between a learning goal orientation and the career striving behaviours of exploration and planning (partially supporting H10). These results also are consistent with social-cognitive career theory, with self-efficacy and outcome expectations being considered the most proximally related variables to goal setting, and striving behaviours being proximal to goals (Bandura, 1986). These results suggest that a learning goal orientation enhances career selfefficacy and outcome expectations, and is indirectly associated with elevated career aspirations, career exploration and planning. One previous study has shown that a learning goal orientation is associated with better career decision-making and more self-exploration (Creed et al., 2011), which suggests that having a learning goal orientation might be associated positively with a wider range of career related variables. We found no such mediation effects for performance-avoid goal orientation. While a performance-avoid orientation was negatively associated with career self-efficacy, there were no indirect effects on career aspirations, career exploration or career planning in our sample. Creed et al. (2011) found negative associations between a performance-avoid orientation and three career goalbased measures (educational aspirations, job aspirations, and job expectations), suggesting that our results in relation to performance-avoid might be sample specific, or that associations might depend on the type of aspirations considered.

Many interventions have been devised that promote the development of a learning orientation in children (e.g., see Kaplan \& Maehr, 2007) and adults (van Hooft \& Noordzij, 2009). While these interventions have focused on educational achievement for children and job seeking for adults, variations on these programs need to be assessed for use in the career development domain with children. More generally, standard career interventions for high school students could profitably incorporate elements of goal orientation management and training. The evidence from our study is that 
fostering a learning goal orientation will be directly associated with enhanced efficacy and outcome expectations, and indirectly associated with elevated goals and increased striving behaviours.

Several authors have characterised performance-avoid orientation as problematic (Brophy, 2004; Payne et al., 2007). This is because the focus for performance-avoid individuals is on trying to avoid negative outcomes, which, in turn, stimulates self-protective strategies, such as being alert to and avoiding threats, being overly concerned with self-presentation, and expending effort on managing anxiety (Elliot \& Harackiewicz, 1996), all of which detract from task engagement, striving and achievement. Young people who rely on a performance-avoid orientation in the career domain might require special assistance to ensure that they have the opportunity to develop appropriate skills and beliefs, and do not, for example, foreclose on a career too early to avoid the stress associated with career exploration, planning and decision-making. Payne et al. (2007) described goal orientation as a malleable construct, meaning that young people with this avoidant orientation are likely to respond to targeted interventions around goal orientation. We found that a performance-avoid orientation was associated with lower self-efficacy. Addressing an avoidant orientation in young people is likely to have direct benefits for their career confidence levels.

We found no relationship between a performance-prove orientation and any of the career variables $(\mathrm{H} 2)$. Previous studies have shown a positive effect for a performance-prove orientation in a range of achievement situations, although the effects were stronger in situations where achievement tasks were simpler and outcome success could be more readily obtained (Utman, 1997). Career development tasks are not simple, and outcomes are largely distal to behaviours for young people; thus, there are fewer opportunities for performance-prove individuals to demonstrate competence and receive favourable feedback from others on their behaviours. Consistent with this, Creed et al. (2009) found a learning goal orientation associated with four of the career variables used in their study (self-exploration, career 
exploration, career decision-making, and self-regulation); whereas they found only one association for a performance-prove orientation, with career decision-making. It is possible that those with a performance-prove orientation are not engaging in the career development process in the same (positive) way as learning oriented youth (and are not avoiding it as performance-avoid youth might), as there are not the same benefits for engaging in career processes. If this is the case, then young people with this type of approach orientation would benefit also from strategies that would foster a learning approach in them.

\section{Limitations and Future Research}

Both learning and performance-avoid orientations have been construed by others as part of a cluster of important career adaptability behaviours (Payne et al., 2007). Career adaptability is growing in importance as a vocational process, and future research needs to test the association between goal orientation and other adaptability behaviours. Consistent with this, Payne et al. (2007) found that a learning orientation was associated with more feedback seeking, another important adaptive/regulatory strategy. Other researchers have shown that goal orientation is not stable in childhood, and might, for example, be influenced by critical school events, such as transitioning from middle to high school (Anderman \& Anderman, 1999). Future research needs to examine the effect any change in goal orientation has on career trajectories. Further, it has been suggested that goal orientation can be decomposed into state and trait aspects, in the same way, for example, that self-efficacy can be considered as general and task-specific (Payne et al., 2007). The questions for career theorists and practitioners are which decomposition is most salient to which aspect of career development, and does a particular goal orientation have equally promoting/demoting effects on all areas of career development and career-decision making. Some authors (see Payne et al., 2007) have suggested also that a learning goal orientation can be split into learning-perform and learning-avoid, in the same way that the 
performance orientation has been considered as two independent constructs. Future research should test this finer grained analysis of goal orientation to determine if this approach adds to our understanding in the career area. Temporal relationships need to be tested also. This was not possible in the current study, which collected data at one point in time. We found the hypothesised model to be the best fitting model of the three alternatives tested, but goal orientation might not always be an antecedent to all career behaviours; it might be, for example, that particular positive (or poor) career experiences will lead to changes in goal orientation, general or specific, to career development. Finally, we used self-report scales to assess a single sample of Australian children. Future studies need to replicate these findings on different samples, and ideally include other- as well as self-report measures to bolster the validity of the results.

\section{Conclusion}

In summary, we found that a learning orientation was associated directly, and positively, with career self-efficacy and outcome expectations, and associated indirectly, and positively, with career aspirations, career exploration and career planning: attitudes and behaviours that should stand young people in good stead for achieving career goals in the long run. We found also that a performance-avoid orientation was associated directly, and negatively, with career self-efficacy; that is, these adolescents also reported lower levels of confidence in the career domain, which reflects an orientation and belief system that is likely to hamper their career development and potentially disadvantage their future achievements. These results suggest that goal orientation might be an important variable to consider when examining career development, and might be important practically when assisting young people with their career progress and decision-making.

\section{References}


Anderman, L. H., \& Anderman, E. M. (1999). Social predictors of change in students' achievement goal orientations. Contemporary Educational Psychology, 24, 21-37. doi:10.1006/ceps.1998.0978

Bandura, A. (1986). Social foundations of thought and action: A social cognitive theory. Englewood Cliffs, NJ: Prentice Hall.

Betz, N. E., \& Hackett, G. (2006). Career self-efficacy theory: Back to the future. Journal of Career Assessment, 14, 3-11. doi:10.1177/1069072705281347

Blustein, D. L. (1997). A context-rich perspective of career exploration across the life roles. Career Development Quarterly, 45, 260-274. Retrieved from http://associationdatabase.com/aws/NCDA/pt/sp/cdquarterly

Brophy, J. (2004). Motivating students to learn (2 ${ }^{\text {nd }}$ Ed.). Mahwah, NJ: Erlbaum.

Byrne, B. (2010). Structural equation modelling with AMOS ( $2^{\text {nd }}$ ed.). Ottawa, Canada: Routledge.

Covington, M. V. (2000). Goal theory, motivation, and school achievement: An integrative review. Annual Review of Psychology, 51, 171-200. doi:10.1146/annurev.psych.51.1.171

Creed, P. A., Searle, J., \& Rogers, M E. (2010). Medical specialty prestige and lifestyle preference for medical students. Social Science and Medicine, 71, 1084-1088. doi:10.1016/j.socscimed.2010.06.027

Creed, P. A., Fallon, T., \& Hood, M. (2009). The relationship between career adaptability, person and situation variables, and career concerns in young adults. Journal of Vocational Behavior, 74, 219-229. doi:10.1016/j.jvb.2008.12.004

Creed, P. A., \& Patton, W. (2004). The development and validation of a short form of the Career Development Inventory - Australia. Australian Journal of Guidance and Counselling, 14, 125-138. Retrieved from 
www.australianacademicpress.com.au/Publications/Journals/Guidance\&Counselling/guidecounsel.ht $\mathrm{m}$

Creed, P. A., Tilbury, C., Buys, N., Crawford, M. (2011). Cross-lagged relationships between career aspirations and goal orientation in early adolescents. Journal of Vocational Behavior, 78, 92-99. doi:10.1016/j.jvb.2010.09.010

Davis, W., Carson, C., Ammeter, A., \& Treadway, D. (2005). The interactive effects of goal orientation and feedback specificity on task performance. Human Performance, $\quad$ 409-426. doi:10.1207/s15327043hup1804_7

Dweck, C. S. (1986). Motivational processes affecting learning. American Psychologist, 41, 1040-1048. doi:10.1037/0003-066X.41.10.1040

Dweck, C. S., \& Leggett, E. L. (1988). A social-cognitive approach to motivation and personality. Psychological Review, 95, 256-273. doi:10.1037/0033-295X.95.2.256

Elliot, A. J., \& Harackiewicz, J. M. (1996). Approach and avoidance achievement goals and intrinsic motivation: A mediational analysis. Journal of Personality and Social Psychology, $\quad 70, \quad 461-475$. Retrieved from http://psycnet.apa.org/journals/psp/70/3/

Elliot, A. J., Shell, M., Bouas Henry, K., \& Maier, M. (2005). Achievement goals, performance contingencies, and performance attainment: An experimental test. Journal of Educational Psychology, 97, 630-640. doi:10.1037/0022-0663.97.4.630

Elliot, A. J., \& Thrash, T. M. (2002). Approach-avoidance motivation in personality: Approach and avoidance temperaments and goals. Journal of Personality \& Social Psychology, $\quad 82, \quad 804-818$. doi:10.1037/0022-3514.82.5.804 
Fouad, N. A., Smith, P. L., \& Enochs, L. G. (1997). Reliability and validity evidence for the middle school self-efficacy scale. Measurement and Evaluation in Counseling and Development, 30, 17-31. Retrieved from http://mec.sagepub.com/

Gray, M. P., \& O'Brien, K. M. (2007). Advancing the assessment of women's career choices: The Career Aspiration Scale. Journal of Career Assessment, 15, 317-337. doi:10.1177/1069072707301211

Hall, D. T. (2002). Careers in and out of organizations. San Francisco, CA: Jossey-Bass.

Hirschi, A. (2009). Career adaptability development in adolescence: Multiple predictors and effect on sense of power and life satisfaction. Journal of Vocational Behavior, 74, 145-155. doi:10.1016/j.jvb.2009.01.002

Jackson, C. J., Hobman, E. V., Jimmieson, N. L., \& Martin, R. (2009). Comparing different approach and avoidance models of learning and personality in the prediction of work, university, and leadership outcomes. British Journal of Psychology, 100, 283-312. doi:10.1348/000712608×322900

Kanfer, R., Wanberg, C. R., \& Kantrowitz, T. M. (2001). Job search and employment: A personalitymotivational analysis and meta-analytic review. Journal of Applied Psychology, 86, 837-855. doi:10.1037//0021-9010.86.5.837

Kaplan, A., \& Maehr, M. L. (2007). The contributions and prospects of goal orientation. Educational Psychology Review, 19, 141-184. doi:10.1007/s10648-006-9012-5

Kline, R. B. (2011). Principles and practice of structural equation modelling ( $3^{\text {rd }}$ ed.). New York, NY: The Guilford Press. 
Landis, R. S., Beal, D. J., \& Tesluck, P. E. (2000). A comparison of approaches to forming composite measures in structural equation models. Organizational Research Methods, 3, 186-207. doi:10.1177/109442810032003

Lent, R. W. (2005). A social cognitive view of career development and counseling. In S. D. Brown \& R. W. Lent (Eds.), Career development and counseling: Putting theory and research to work (pp. 101-125). Hoboken, NJ: Wiley \& Sons.

Lent, R. W., Brown, S. D., \& Hackett, G. (1996). Career development from a social cognitive perspective. In D. Brown \& L. Brooks (Eds.), Career choice and development (pp. 373-421). San Francisco, CA: Jossey-Bass Inc.

Lent, R. W., Brown, S. D., \& Hackett, G. (2000). Contextual supports and barriers to career choice: A social cognitive analysis. Journal of Counseling Psychology, 47, 36-49. doi:10.1037/0022-0167.47.1.36

Locke, E. A., \& Latham, G. P. (2002). Building a practically useful theory of goal setting and task motivation: A 35-year odyssey. American Psychologist, 57, 705-717. doi:10.1037//0003066X.57.9.705

Lokan, J. (1984). Manual of the Career Development Inventory - Australian Edition. Melbourne: ACER.

Lord, R. G., Diefendorff, J. M., Schmidt, A. M., \& Hall, R. J. (2010). Self-regulation at work. Annual Review of Psychology, 61, 543-568. doi:10.1146/annurev.psych.093008.100314

Maes, S., \& Karoly, P. (2005). Self-regulation assessment and intervention in physical health and illness: A review. Applied Psychology: An International Review, 54, 267-299. doi:10.1111/j.14640597.2005.00210.x 
Mau, W., \& Bikos, L. H. (2000). Educational and vocational aspirations of minority and female students: A longitudinal study. Journal of Counseling \& Development, 78, 186-194. Retrieved from http://www.counseling.org/Publications/Journals.aspx

Middleton, M. J., \& Midgley, C. (1997). Avoiding the demonstration of lack of ability: An underexplored aspect of goal theory. Journal of Educational Psychology, 89, 710-718. doi:10.1037/00220663.89.4.710

Midgley, C., Kaplan, A., Middleton, M., Maehr, M. L., Urdan, T., Anderman, L. H., ...Roeser, R. (1998). The development and validation of scales assessing students' achievement goal orientations. Contemporary Educational Psychology, 23, 113-131. doi:10.1006/ceps.1998.0965

O'Brien, K. M. (1996). The influence of psychological separation and parental attachment on the career development of adolescent women. Journal of Vocational Behavior, 48, 257-274. doi:10.1006/jvbe.1996.0024

Payne, S. C., Youngcourt, S. S., \& Beaubien, J. M. (2007). A meta-analytic examination of the goal orientation nomological net. Journal of Applied Psychology, 92, 128-150. doi:10.1037/00219010.92.1.128

Roth, P. L., Switzer, F. S., \& Switzer, D. M. (1999). Missing data in multiple item scales: A monte carlo analysis of missing data techniques. Organizational Research Methods, 2, 211-212. doi:10.1177/109442819923001

Rottinghaus, P. J., Day, S. X., \& Borgen, F. H. (2005). The Career Futures Inventory: A measure of careerrelated adaptability and optimism. Journal of Career Assessment, 13, 3-24. doi:10.1177/1069072704270271 
Rojewski, J. W. (2005). Occupational aspirations: Constructs, meaning and application. In S. D. Brown \& R. W. Lent, Career development and counselling: Putting theory and research to work (pp. 131-154). NJ: John Wiley \& Sons.

Savickas, M. L. (1997). Career adaptability: An integrative construct for life-span, life-space theory. The Career Development Quarterly, 45, 247-259. Retrieved from http://associationdatabase.com/aws/NCDA/pt/sp/cdquarterly

Schoon, I., \& Parsons, S. (2002). Teenage aspirations for future careers and occupational outcomes. Journal of Vocational Behavior, 60, 262-288. doi:10.1006/jvbe.2001.1867

Shrout, P. E., \& Bolger, N. (2002). Mediation in experimental and nonexperimental studies: New procedures and recommendations. Psychological Methods, 7, 422-445. doi:10.1037/1082989X.7.4.422

Taylor, K. M., \& Betz, N. E. (1983). Applications of self-efficacy theory to the understanding and treatment of career indecision. Journal of Vocational Behavior, 22, 63-81. doi:10.1016/00018791(83)90006-4

Urdan, T., \& Midgley, C. (2003). Changes in the perceived classroom goal structure and pattern of adaptive learning during early adolescence. Contemporary Educational Psychology, 28, 524-551. doi:10.1016/SO361-476X(02)00060-7

Utman, C. H. (1997). Performance effects of motivational state: A meta-analysis. Personality and Social Psychology Review, 1, 170-182. doi:10.1207/s15327957pspr0102_4

Valentini, N. C., \& Rudisill, M. E. (2006) Goal orientation and mastery climate: A review of contemporary research and insights to intervention. Estudos de Psicologia, 23, 159-172. doi:10.1590/S0103$166 \times 2006000200006$ 
VandeWalle, D. (1997). Development and validation of a work domain goal orientation instrument. Educational and Psychological Measurement, 57, 995-1015. doi:10.1177/0013164497057006009

VandeWalle, D., Brown, S. P., Cron, W. L., \& Slocum, J. W. (1999). The influence of goal orientation and self-regulation tactics on sales performance: A longitudinal field test. Journal of Applied Psychology, 84, 249-259. doi:10.1037/0021-9010.84.2.249

Van Hooft, E. A. J., \& Noordzij, G. (2009). The effects of goal orientation on job search and reemployment: A field experiment among unemployed job seekers. Journal of Applied Psychology, 94, 1581-1590. doi:10.1037/a0017592

Yeo, G. B., Sorbello, T., Koy, A., \& Smillie, L. D. (2008). Goal orientation profiles and task performance growth. Motivation and Emotion, 32, 296-309. doi:10.1007/s11031-008-9099-8

Zikic, J., Klehe, U. (2006). Job loss as a blessing in disguise: The role of career exploration and career planning in predicting reemployment quality. Journal of Vocational Behavior, 69, 391-409. doi:10.1016/j.jvb.2006.05.007 


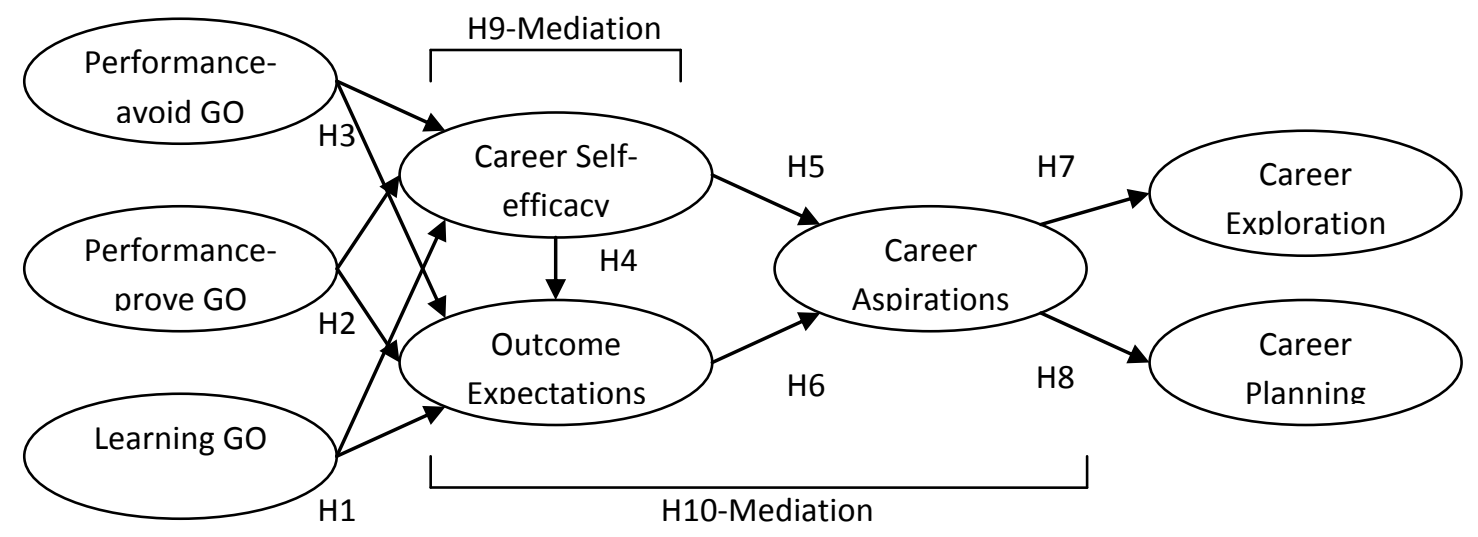

Figure 1. Hypothesised model, with career self-efficacy and outcome expectations mediating the relationship between goal orientation and career aspirations, and career self-efficacy, outcome expectations and career aspirations mediating the relationship between goal orientation and career exploration and planning. 


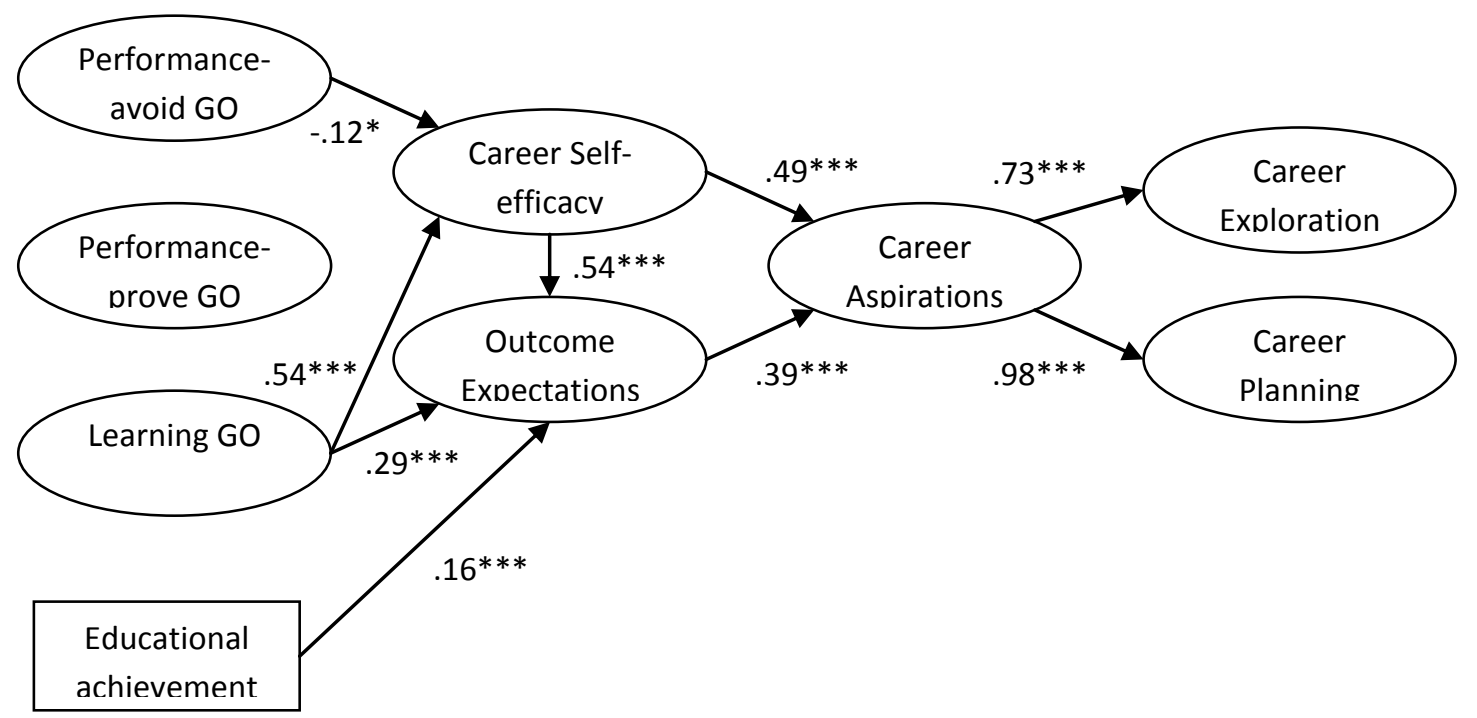

Figure 2. Simplified final model, reported with standardised regression weights. 
Table 1

Means, Standard Deviations, Zero-Order Correlations (below diagonal), and Correlations among Latent Variables (above diagonal); $(N=280)$

\begin{tabular}{|c|c|c|c|c|c|c|c|c|c|c|c|}
\hline Variables & $M$ & $S D$ & 1 & 2 & 3 & 4 & 5 & 6 & 7 & 8 & 9 \\
\hline 1. Learning GO & 11.01 & 2.57 & - & $.47 * * *$ & -.14 & $.53 * * *$ & $.63 * * *$ & $.41^{* * *}$ & $.49 * * *$ & $.60 * * *$ & $.45^{* * *}$ \\
\hline 2. Performance-prove GO & 10.47 & 2.69 & $.35^{* * *}$ & - & $.32 * * *$ & $.31 * * *$ & $32 * * *$ & $.34 * * *$ & $.28 * * *$ & $.29 * * *$ & $.22 * *$ \\
\hline 3. Performance-avoid GO & 8.29 & 2.45 & -.02 & $.28 * * *$ & - & $-.21 * *$ & $-.30 * * *$ & -.15 & .03 & -.04 & $-.30 * * *$ \\
\hline 4. Self-efficacy & 34.06 & 6.74 & $.45^{* * *}$ & $.25 * * *$ & $-.13^{*}$ & - & $.77 * * *$ & $.61^{* * *}$ & $.64 * * *$ & $.79 * * *$ & $.31 * * *$ \\
\hline 5. Outcome expectations & 37.89 & 5.43 & $.54 * * *$ & $.26 * * *$ & $-.19 * *$ & $.71 * * *$ & - & $.67^{* * *}$ & $.63 * * *$ & $.72 * * *$ & $.45^{* * *}$ \\
\hline 6. Career aspirations & 15.95 & 2.76 & $.35^{* * *}$ & $.24 * * *$ & $-.12 *$ & $.54 * * *$ & $.59 * * *$ & - & $.62 * * *$ & $.56 * * *$ & $.22 * * *$ \\
\hline 7. Career exploration & 26.37 & 6.51 & $.40 * * *$ & $.22 * * *$ & .04 & $.51^{* * *}$ & $.53^{* * *}$ & $.47^{* * *}$ & - & $.76^{* * *}$ & $.16^{*}$ \\
\hline 8. Career planning & 35.73 & 8.04 & $.46 * * *$ & $.21 * * *$ & -.01 & $.69 * * *$ & $.66^{* * *}$ & $.47^{* * *}$ & $.60 * * *$ & - & $.29 * * *$ \\
\hline 9. Education achievement & 3.86 & .87 & $.40 * * *$ & $.18^{*}$ & $-.23 * * *$ & $.30 * * *$ & $.42 * * *$ & $.19 * *$ & $.13^{*}$ & $.26 * * *$ & - \\
\hline 10. Age & 15.26 & 1.22 & -.08 & -.10 & -.09 & .05 & -.04 & .06 & .11 & .07 & $-.19 * *$ \\
\hline 11. Gender & - & - & .09 & .01 & .07 & .05 & .01 & .09 & .07 & .05 & -.02 \\
\hline
\end{tabular}

$*=p<.05 ; * *=p<.01 ; * * *=p<.001$ 